\title{
Two grams of sarcosine in schizophrenia - is it too much? A potential role of glutamate- serotonin interaction
}

This article was published in the following Dove Press journal:

Neuropsychiatric Disease and Treatment

4 February 2014

Number of times this article has been viewed

\author{
Dominik Strzelecki \\ Justyna Szyburska \\ Jolanta Rabe-Jabłońska \\ Department of Affective and \\ Psychotic Disorders, Central Clinical \\ Hospital, Medical University of Łódź, \\ Łódź, Poland
}

\begin{abstract}
Glutamate is the main excitatory neurotransmitter in the central nervous system. Dysfunction of the glutamatergic system plays an important role in the pathogenesis of schizophrenia. Therefore, glutamatergic agents such as N-methyl-D-aspartate receptor coagonists (ie, glycine, D-cycloserine) and glycine transporter type 1 inhibitors (eg, sarcosine) are studied for their efficacy in ameliorating negative and cognitive symptomatology in patients with schizophrenia. We report the case of a 23 -year-old schizophrenic patient treated with quetiapine and citalopram, who was offered concomitant sarcosine treatment. After obtaining an informed consent, we started administration of $2 \mathrm{~g}$ of sarcosine per day to treat persistent negative and cognitive symptoms. The patient's activity and mood improved within 2 weeks, but in the following 2 weeks the patient reported increased drive, activity, libido, unpleasant inner tension, and irritability. We ruled out hypomania and decided to decrease the daily dose of sarcosine to $1 \mathrm{~g}$, which resulted in reduction of drive and irritability. Activity and mood improved compared with his state before adding sarcosine. We suggest a sarcosine dose between $1 \mathrm{~g}$ and $2 \mathrm{~g}$ per day with an initial dose of $2 \mathrm{~g}$, but if side effects occur, the dose should be decreased to $1 \mathrm{~g}$ per day. We would like to emphasize the clinically important glutamate-serotonin interaction during concomitant use of sarcosine, citalopram, and quetiapine in our patient, which may lead to serious discomfort.
\end{abstract}

Keywords: schizophrenia, glutamatergic system, serotoninergic system, sarcosine, NMDA receptor, dose finding

\section{Introduction}

The glutamatergic system is the main excitatory system of the human brain. Dysfunction of glutamatergic transmission is involved in the pathogenesis of schizophrenia, neurodegenerative disorders, and addictions. ${ }^{1-5}$ Pharmacological interventions in schizophrenia are currently focused on enhancing the activity of the N-methyl-D-aspartate (NMDA) receptor, one of the subtypes of glutamatergic ionotropic receptors. There are two known options for influencing the NMDA receptor via the glycine site that are currently under clinical investigation; the direct method consists of administration of glycine or another NMDA receptor co-agonist, such as D-cycloserine and D-serine, and the indirect method consists of inhibiting the glycine transporter type I (GlyT1) with sarcosine, RG1678 (bitopertin), or ALX-5407. ${ }^{6-9}$ Sarcosine has been used in several small studies, ${ }^{10-14}$ and the results seem to be promising in treating negative symptoms and cognitive dysfunction where the benefits of known antipsychotics are very limited. ${ }^{15,16}$ Previous studies also indicate improvement in depressive symptomatology during the use of NMDA co-agonists and sarcosine,${ }^{17-22}$ and interestingly NMDA receptor antagonists (ketamine,
Correspondence: Dominik Strzelecki Department of Affective and Psychotic Disorders, Medical University of Łódź, Central Clinical Hospital, ul. Czechosłowacka 8/10, 92-216 Łódź, Poland $\mathrm{Tel}+48426757236$

Fax +48426757403

Email dominik.strzelecki@umed.lodz.pl 
memantine) also exhibit some antidepressive properties. ${ }^{23-25}$ Other substances modifying function of the glutamatergic system, such as modulators of metabotropic glutamate receptors and ampakines (CX516), are under investigation. ${ }^{26,27}$ Sarcosine (N-methylglycine, a natural amino acid) is considered one of the most effective glutamate-related methods of treatment augmentation when used with neuroleptics, and a significant improvement in both negative symptom and total symptom scores on the Positive and Negative Syndrome Scale has been noted. ${ }^{16,17}$ In the published studies, patients received a $2 \mathrm{~g}$ dose of sarcosine per day, established on the basis of the results of a small open-label study in which patients were administered three doses of the amino acid (10-30 mg/kg of body mass per day). ${ }^{10-14}$

We present a case of a schizophrenic patient in a stable mental condition who started taking $2 \mathrm{~g}$ of sarcosine per day. After an initial improvement, he developed symptoms of psychomotor agitation and it was necessary to decrease the dose of sarcosine. This observation indicates a need for revision of the recommended dosing of sarcosine and, as with other drugs, to determine a range of doses for this substance. For an effective and well tolerated treatment, we suggest a dose between $1 \mathrm{~g}$ and $2 \mathrm{~g}$ of sarcosine per day, depending on the patient's feedback. We consider these observations to be important also because patients from different countries enquire about sarcosine, and the indications for its use, dosing, and adverse effects. These questions can also be directed to other doctors.

\section{Case report}

The patient was a 23-year-old male suffering from schizophrenia for 5 years (diagnosed according to the International Classification of Diseases-Tenth Revision), who had undergone psychiatric hospitalization four times in the past, most recently 3 years earlier. The first episode involved a picture of typical paranoid syndrome and was induced by amphetamines. Subsequent psychotic episodes were not related to drug use. During a stable period, the patient presented mild severity of negative (blunted and inappropriate affect, social withdrawal) and depressive symptoms and moderate cognitive problems (memory and attention), which were the main indication for administration of sarcosine. Among positive symptomatology, the patient described only periodic mild racing thoughts without typical delusions or hallucinations. Both parents were diagnosed with schizophrenia. After receiving information about sarcosine, the patient signed an informed consent form and started receiving the amino acid. Basic laboratory tests were performed (complete blood count, electrolytes, liver and renal parameters, lipids, prolactin, and thyroid stimulating hormone), which showed no deviations from reference values. The patient had no neurological, endocrine, or other chronic comorbidities at the time of treatment. We excluded ongoing alcohol and drug dependence or use in the previous 6 months (using a panel drug testing), but the patient smoked about 15 cigarettes per day. He was unemployed at that time and on a disability living allowance. Before addition of sarcosine, the patient has been receiving quetiapine $500 \mathrm{mg}$ per day for 2 years and citalopram $10 \mathrm{mg}$ per day for several months. Citalopram was prescribed due to panic attacks and negative symptoms. ${ }^{28}$

During the first 2 weeks of sarcosine administration at $2 \mathrm{~g}$ per day, the patient reported improvement in overall activity, concentration, and mood. After a further 2 weeks, he reported moderate inner tension with mildly increased drive, excessive activity and irritability, and a significant increase in sexual tension. Further examination ruled out a diagnosis of hypomania. The patient found these symptoms to be very unpleasant and asked for modification of his treatment. The overall impact of sarcosine he described as positive, and therefore it was decided to maintain the sarcosine supplementation but to reduce the dose by half to $1 \mathrm{~g}$ per day. After lowering the dose of sarcosine without changes in the dosage of his concomitant medications, the intensity of his excitation and irritability decreased, and the patient subjectively described his overall mental state as better in comparison with the period before sarcosine and treatment with $2 \mathrm{~g}$ of the amino acid (see Table 1). There were no external circumstances to explain the observed intensity of psychomotor agitation symptoms.

\section{Discussion}

Substances that modify functioning of the glutamatergic system in psychiatric disorders are under increasing investigation. ${ }^{29}$ The efficacy of sarcosine and other glycine transporter inhibitors, such as RG1678, in the treatment of schizophrenia is currently being assessed. ${ }^{30,31}$ Although there have been very few studies in this area, it is considered that these compounds may have beneficial effects on the symptomatology of schizophrenia, particularly on negative symptoms, affective symptoms, and disturbed cognitive functioning. The signs of excessive psychomotor agitation described in this patient have not been previously described in any patient taking sarcosine. In addition to the direct excitatory effect of sarcosine, possible reasons for these symptoms in our patient may relate to amino acid-induced 
Table I Psychiatric assessment scores

\begin{tabular}{lllll}
\hline & $\begin{array}{l}\text { Before } \\
\text { sarcosine }\end{array}$ & $\begin{array}{l}\text { Sarcosine } \\
\mathbf{2} \mathbf{g}\end{array}$ & $\begin{array}{l}\text { Sarcosine } \\
\text { end of } \mathbf{2} \mathbf{~ g}\end{array}$ & $\begin{array}{l}\text { Sarcosine } \\
\mathbf{I ~} \mathbf{g}\end{array}$ \\
\hline PANSS P & 9 & 9 & 12 & 9 \\
PANSS N & 22 & 19 & 16 & 17 \\
PANSS G & 42 & 29 & 34 & 28 \\
PANSS T & 73 & 57 & 63 & 54 \\
Calgary & 4 & 5 & 4 & 3 \\
HAMA & 7 & 16 & 12 & 9 \\
\hline
\end{tabular}

Notes: The first visit was before the start of sarcosine. The second visit was after 2 weeks of taking the $2 \mathrm{~g}$ dose of aminoacid. On the third visit, after a further 2 weeks, the dose was reduced. After a further 2 weeks, on the fourth visit, the patient was taking I g of sarcosine.

Abbreviations: PANSS, Positive and Negative Symptoms of Schizophrenia; P, positive; N, negative; G, general psychopathology; T, total score; Calgary, Calgary Scale for Depression in Schizophrenia; HAMA, Hamilton Anxiety Scale.

primary or secondary potentiation of serotonergic transmission, that had previously been increased with selective serotonin reuptake inhibitors and quetiapine (which also has dopaminergic and cholinergic properties). The observed clinical picture in fact resembles symptoms associated with initiation of a selective serotonin reuptake inhibitor or serotonin-norepinephrine reuptake inhibitor, which was not present during use of citalopram and quetiapine in our patient. Mechanisms of the glutamatergic impact on serotoninergic function are currently not clear. We cannot clearly explain the 2-week delay in appearance of discomfort after starting sarcosine, but this period is similar to the delayed effect of selective serotonin reuptake inhibitors and other antidepressants. In addition to receptor-dependent modulation of neurotransmission, another hypothetical mechanism involves an interaction between sarcosine and citalopram or quetiapine, eg, at the level of cytochrome P450 metabolism.

The situation described here indicates a need to determine the range of sarcosine doses used in augmentation of treatment for schizophrenia. We suggest considering a more flexible use of sarcosine in the range of 1-2 g per day, particularly in combination with serotoninergic substances. Of course, flexible adjusting of the dose of selective serotonin reuptake inhibitor or other serotoninergic substances can also be considered.

In conclusion, we believe that appropriate simultaneous use of substances with glutamatergic and serotoninergic properties may generate a synergistic antidepressive and activating effect. ${ }^{32}$ Due to the methodological limitations of case reports, any conclusions need to be formulated carefully. Assessment of serum glycine and sarcosine levels and metabolite changes on nuclear magnetic resonance spectroscopy would have enriched this report.
The patient described here was included in the run-up to the PULSAR (PoLish SARcosine study in schizophrenia) study, which will evaluate the efficacy and safety of sarcosine in patients with schizophrenia. The PULSAR study had been reviewed by the ethics committee at the Medical University of Łódź and had therefore been performed in accordance with the ethical standards laid down in the 1975 Declaration of Helsinki. A detailed description of the study can be found at Clinicaltrials.gov site. ${ }^{33}$

\section{Acknowledgment}

The study is supported by the Polish Ministry of Science and Higher Education (N402 268836).

\section{Disclosure}

The authors have no conflicts of interest in this work.

\section{References}

1. Carlsson A, Waters N, Waters S, Carlsson ML. Network interactions in schizophrenia - therapeutic implications. Brain Res Brain Res Rev. 2000;31:342-349.

2. Coyle JT. The glutamatergic dysfunction hypothesis for schizophrenia. Harv Rev Psychiatry. 1996;3:241-253.

3. Olney JW, Newcomer JW, Farber NB. NMDA receptor hypofunction model of schizophrenia. J Psychiatr Res. 1999;33:523-533.

4. Hu NW, Ondrejcak T, Rowan MJ. Glutamate receptors in preclinical research on Alzheimer's disease: update on recent advances. Pharmacol Biochem Behav. 2012;100:855-862.

5. Mann K, Kiefer F, Spanagel R, Littleton J. Acamprosate: recent findings and future research directions. Alcohol Clin Exp Res. 2008;32: 1105-1111.

6. Kantrowitz J, Javitt DC. Glutamatergic transmission in schizophrenia: from basic research to clinical practice. Curr Opin Psychiatry. 2012;25: $96-102$.

7. de Bartolomeis A, Sarappa C, Magara S, Iasevoli F. Targeting glutamate system for novel antipsychotic approaches: relevance for residual psychotic symptoms and treatment resistant schizophrenia. Eur $J$ Pharmacol. 2012;682:1-11.

8. López-Muñoz F, Álamo C. Neurobiological background for the development of new drugs in schizophrenia. Clin Neuropharmacol. 2011;34:111-126.

9. Tuominen HJ, Tiihonen J, Wahlbeck K. Glutamatergic drugs for schizophrenia. Cochrane Database Syst Rev. 2006;19:CD003730.

10. Tsai G, Lane HY, Yang P, Chong MY, Lange N. Glycine transporter I inhibitor, N-methylglycine (sarcosine) added to antipsychotics for the treatment of schizophrenia. Biol Psychiatry. 2004;55:452-456.

11. Lane HY, Chang YC, Liu YC, Chiu CC, Tsai GE. Sarcosine or D-serine add-on treatment for acute exacerbation of schizophrenia: a randomized, double-blind, placebo-controlled study. Arch Gen Psychiatry. 2005;62:1196-1204

12. Lane HY, Huang CL, Wu PL, Liu YC, Chang YC, Lin PY, Chen PW, Tsai G. Glycine transporter 1 inhibitor, N-methylglycine (sarcosine), added to clozapine for the treatment of schizophrenia. Biol Psychiatry. 2006;60:645-649.

13. Lane HY, Liu YC, Huang CL, Chang YC, Liau CH, Perng CH, Tsai GE. Sarcosine (N-methylglycine) treatment for acute schizophrenia: a randomized, double-blind study. Biol Psychiatry. 2008;63:9-12

14. Lane HY, Lin CH, Huang YJ, Liao CH, Chang YC, Tsai GE. A randomized, double-blind, placebo-controlled comparison study of sarcosine (N-methylglycine) and D-serine add-on treatment for schizophrenia. Int J Neuropsychopharmacol. 2010;13:451-460. 
15. Hashimoto K, Malchow B, Falkai P, Schmitt A. Glutamate modulators as potential therapeutic drugs in schizophrenia and affective disorders. Eur Arch Psychiatry Clin Neurosci. 2013;263:367-377.

16. Singh SP, Singh V. Meta-analysis of the efficacy of adjunctive NMDA receptor modulators in chronic schizophrenia. CNS Drugs. 2011;25:859-885

17. Tsai GE, Lin PY. Strategies to enhance N-methyl-D-aspartate receptormediated neurotransmission in schizophrenia, a critical review and meta-analysis. Curr Pharm Des. 2010;16:522-537.

18. Heresco-Levy U, Ermilov M, Shimoni J, Shapira B, Silipo G, Javitt DC. Placebo-controlled trial of D-cycloserine added to conventional neuroleptics, olanzapine, or risperidone in schizophrenia. Am J Psychiatry. 2002; 159:480-482.

19. Heresco-Levy U, Javitt DC, Ermilov M, Silipo G, Shimoni J. Doubleblind, placebo-controlled, crossover trial of D-cycloserine adjuvant therapy for treatment-resistant schizophrenia. Int J Neuropsychopharmacol. 1998;1:131-135.

20. Heresco-Levy U, Javitt DC, Ermilov M, Mordel C, Horowitz A, Kelly D. Double-blind, placebo-controlled, crossover trial of glycine adjuvant therapy for treatment-resistant schizophrenia. $\mathrm{Br} J$ Psychiatry. 1996;169:610-617.

21. Strzelecki D, Kropiwnicki P, Rabe-Jabłońska J. [Augmentation of antipsychotics with glycine may ameliorate depressive and extrapyramidal symptoms in schizophrenic patients: a preliminary 10-week open-label study]. Psychiatr Pol. 2013;47:609-620. Polish.

22. Huang CC, Wei IH, Huang CL, et al. Inhibition of glycine transporter-I as a novel mechanism for the treatment of depression. Biol Psychiatry. 2013;74:734-741

23. Diazgranados N, Ibrahim L, Brutsche NE, et al. A randomized add-on trial of an N-methyl-D-aspartate antagonist in treatment-resistant bipolar depression. Arch Gen Psychiatry. 2010;67:793-802.

24. Ferguson JM, Shingleton RN. An open-label, flexible-dose study of memantine in major depressive disorder. Clin Neuropharmacol. 2007;30:136-144.
25. Muhonen LH, Lönnqvist J, Juva K, Alho H. Double-blind, randomized comparison of memantine and escitalopram for the treatment of major depressive disorder comorbid with alcohol dependence. J Clin Psychiatry. 2008;69:392-399.

26. Pilc A, Chaki S, Nowak G, Witkin JM. Mood disorders: regulation by metabotropic glutamate receptors. Biochem Pharmacol. 2008;75: 997-1006.

27. Arai AC, Kessler M. Pharmacology of ampakine modulators: from AMPA receptors to synapses and behavior. Curr Drug Targets. 2007;8: 583-602.

28. Singh SP, Singh V, Kar N, Chan K. Efficacy of antidepressants in treating the negative symptoms of chronic schizophrenia: meta-analysis. $\mathrm{Br} J$ Psychiatry. 2010;197:174-179.

29. Javitt DC. Glycine transport inhibitors in the treatment of schizophrenia. Handb Exp Pharmacol. 2012;213:367-399.

30. Alberati D, Moreau JL, Lengyel J, et al. Glycine reuptake inhibitor RG1678: a pharmacologic characterization of an investigational agent for the treatment of schizophrenia. Neuropharmacology. 2012;62: 1152-1161.

31. Hopkins CR. ACS Chemical neuroscience molecule spotlight on RG1678. ACS Chem Neurosci. 2011;2:685-686.

32. de Bartolomeis A, Buonaguro EF, Iasevoli F. Serotonin-glutamate and serotonin-dopamine reciprocal interactions as putative molecular targets for novel antipsychotic treatments: from receptor heterodimers to postsynaptic scaffolding and effector proteins. Psychopharmacology (Berl). 2013;225:1-19.

33. Medical Universtity of Lodz. Effect of Sarcosine on Symptomatology, Quality of Life, Oxidative Stress and Glutamatergic Parameters in Schizophrenia (PULSAR). Available from: http://clinicaltrials. gov/show/NCT01503359. NLM identifier: NCT01503359. Accessed December 12, 2013
Neuropsychiatric Disease and Treatment

\section{Publish your work in this journal}

Neuropsychiatric Disease and Treatment is an international, peerreviewed journal of clinical therapeutics and pharmacology focusing on concise rapid reporting of clinical or pre-clinical studies on a range of neuropsychiatric and neurological disorders. This journal is indexed on PubMed Central, the 'PsycINFO' database and CAS.

\section{Dovepress}

The manuscript management system is completely online and includes a very quick and fair peer-review system, which is all easy to use. Visit http://www.dovepress.com/testimonials.php to read real quotes from published authors. 